\title{
Tuberculosis is a global health issue: challenges and need for new tools
}

\author{
Mario C Raviglione \\ From Immunodiagnosis of Tuberculosis: New Questions, New Tools \\ Virginia, VA, USA. 21-23 September 2008
}

Every year, more than 9 million people are affected by tuberculosis (TB) and 1.8 million die from it. Developing countries are heavily affected. The highest rates per capita are in Africa, but the largest numbers are in Asia, with nearly $60 \%$ of the global burden. TB associated with HIV/AIDS is a huge challenge in Africa and multidrug-resistant TB (MDR-TB) is frequent in the former USSR and parts of Asia. [1]

The United Nations Millennium Development Goal (MDG) related to TB control aims to halt and begin to reverse the incidence of TB by 2015 , and the STOP TB Partnership targets elimination of TB as a major public health problem worldwide by 2050. [2]

The World Health Organization (WHO) has developed a six-point Stop TB Strategy to reach the global targets: (i) pursue high-quality DOTS expansion and enhancement; (ii) address TB/HIV, MDR-TB and other challenges; (iii) contribute to strengthening health systems; (iv) engage all care providers; (v) empower patients with TB; and (vi) enable and promote research. [3]

Progress has been made to date toward achieving the global targets. Compared to performance of control programmes in the mid-1990s, up to 6 million human lives have been saved through the implementation of DOTS, later enhanced to the Stop TB Strategy, since 1995. The global incidence of TB has peaked in 2004, resulting in an earlier achievement of the MDG related to TB control. However, the decline since then has been less than $1 \%$ per year, which is insufficient to seriously target elimination by 2050. [1]

Projections show that, even with the optimization of the current control efforts promoted by the Stop TB Strategy using the tools available today, efforts will result in an incidence of TB by 2050 that is much

Correspondence: raviglionem@who.int

Stop TB Department, World Health Organization, Geneva, Switzerland reduced compared to today, but about 100 times higher than the elimination target. Thus, this target cannot be achieved without addressing critical and urgent needs, such as that interrupting transmission focusing on early case detection among vulnerable groups and accelerating innovation for increased access to the best tools available. Furthermore, new tools are needed if elimination is to be targeted assertively. Today in much of the world, the tool most commonly used to diagnose TB, sputum smear microscopy, is more than 100 years old, detects only half of the TB cases and is often ineffective in diagnosing TB in people with HIV. Rapid molecular tests for drug resistance, although already available, are not widely available in the field. Drugs for treatment, which are decades old, are not compatible with some anti-retrovirals and the treatments for MDR-TB are lengthy, expensive, and toxic. The only vaccine, Bacillus Calmette-Guérin (BCG), that is more than 85 years old, protects infants from the disseminated forms of TB, but provides unreliable protection against adult pulmonary TB - the main source of transmission - and, as a result, has had little impact on the global epidemic.

Therefore, diagnostics must be developed to provide faster detection of all forms of TB (smear positive, smear negative, and MDR-TB) and be useable at point of care. They must provide faster results, and be more sensitive and simpler than microscopy to make them useable. Shorter treatment regimens and more effective MDR-TB care regimens are priorities for drug development. An ideal candidate would shorten the treatment from the current six months to less than two months; have a novel mechanism of action; not interact with anti-retrovirals; be taken orally once daily or intermittently; and be low in cost. The vaccine development pipeline, which is focused on both pre and/or postinfection vaccines, is still weak in research needed for clinical trial activation. 
The priorities to achieve success must include expanding financing for TB research and development partnerships; attracting more researchers in academia and industry into the TB research field; fostering more communication between research and implementation communities; and promoting formation of intergovernmental working groups to expand links across neglected critical areas for health research. The constraints include a recent no-growth in financing from Europe and North America for critical research and development [4]; limited incentives for the private sector to engage more broadly; a lack of clinical trial and manufacturing capacity; and limited operational research capacity and financing.

A "TB Research Movement" has been conceived, the goal of which is to stimulate investments, support efforts, accelerate implementation, and expand the existing portfolio across the research continuum to ensure development of those tools that will be conducive to global elimination of TB by 2050. Its objectives are to provide leadership and advocacy to mobilize increased resources in support of a coherent and comprehensive global TB research agenda; and to provide a forum for funders and implementers of TB research to coordinate plans and actions, with the result of ensuring that research needs are addressed, opportunities prioritized, and gaps filled.

Published: 17 December 2010

\section{References}

1. WHO: Global tuberculosis control - A short update to the 2009 report. HO/HTM/TB/2009.426. Geneva: World Health Organization; 2009.

2. Dye C, Maher D, Weil D, Espinal M, Raviglione M: Targets for global tuberculosis control. Int J Tuberc Lung Dis 2006, 10:460-2.

3. Raviglione MC, Uplekar M: WHO's new StopTB Strategy. Lancet 2006, 367:952-5.

4. Agarwal N, Syed J, Harrington M: Tuberculosis research and development: a critical analysis of funding trends, 2005-2007. New York, NY, USA: Treatment Action Group; 2009 [http://www.treatmentactiongroup.org], Accessed March 2009.

doi:10.1016/S0140-6736(06)68392-X

Cite this article as: Raviglione: Tuberculosis is a global health issue: challenges and need for new tools. BMC Proceedings 2010 4(Suppl 3):O1.
Submit your next manuscript to BioMed Central and take full advantage of:

- Convenient online submission

- Thorough peer review

- No space constraints or color figure charges

- Immediate publication on acceptance

- Inclusion in PubMed, CAS, Scopus and Google Scholar

- Research which is freely available for redistribution

Submit your manuscript at www.biomedcentral.com/submit
C Biomed Central 